\title{
EDITORIAL
}

\section{Cavitary bronchiolitis obliterans organizing pneumonia}

\author{
J.F. Cordier
}

The term bronchiolitis obliterans organizing pneumonia (BOOP) refers to nonspecific pathological abnormalities characterized by the presence of granulation tissue within the lumen of the distal pulmonary airspaces, associating "proliferative" bronchiolitis obliterans and organizing pneumonia which is indeed the major component of the pathological process [1].

Some confusion has resulted from the use of this pathological terminology to describe a clinical syndrome which may be either idiopathic or secondary to many causes, such as infectious agents or drugs. Idiopathic BOOP is now recognized as a well-defined, clinicopathological entity characterized by distinct clinical and imaging features together with BOOP in pulmonary biopsy specimens; this entity is also called cryptogenic organizing pneumonia, which is today the preferred terminology for idiopathic cases [2-4].

The imaging features of BOOP are rather characteristic in the typical pattern of multiple alveolar patchy opacities, which are generally peripheral and often migratory [5]; this pattern is usually associated with an excellent response to corticosteroid treatment and a good prognosis. The diffuse, bilateral, infiltrative pattern is less characteristic, and it is associated with a more uncertain corticosteroid response and prognosis. It is likely that some cases of rapidly progressing disease merely represent the organization of diffuse alveolar damage or an initial phase of subacute idiopathic pulmonary fibrosis. BOOP presenting as solitary pneumonia is characterized at imaging by mass(es) or nodule(s) which are often confused with neoplastic disorders [2, 6-8]. However, many other uncommon imaging patterns may occur, such as the cavitary lesions reported in this issue of the Journal, which may present complex diagnostic pitfalls $[9,10]$.

As mentioned above, BOOP is in no way specific to any disease. It is simply a type of pulmonary inflammatory response to a generally mild alveolar and bronchiolar damage. The integrity of the basal lamina is partially preserved, although gaps in it allow interstitial fibroblastic cells to migrate into the alveolar lumen, where they exhibit the phenotypic modulation characteristic of myofibroblasts. They then deposit connective matrix components, giving rise to the typical intra-alveolar buds of granulation tissue which define BOOP [11]. It is, therefore, not surprising that many types of pulmonary injury may result in BOOP, provided that the insult does not lead to parenchymal necrosis or severe irreversible

Hôpital Cardiovasculaire et Pneumologique Louis Pradel, Université Claude Bernard, 69394 Lyon, France. interstitial fibrosis. However, it would probably be naive to imagine that, although BOOP and pulmonary necrosis are clear-cut and distinct processes, generally exclusive of each other, they can never coexist.

The causes of cavitary lesions on chest imaging are many [12], and BOOP (pathologically defined) may be present in some of them, as either a major or minor finding. Bacterial infections are probably the most common cause, and the cavitation of such round opacities of infectious origin generally results from necrosis. Cavities can, however, sometimes result from pneumatocele formation, as in staphylococcal pyaemia in children. Fungi and parasites may also give rise to pulmonary cavities, and, for example, invasive aspergillosis of the airways may result in bronchiolar-based abscess containing hyphae, Aspergillus bronchiolitis, and organizing pneumonia [13]. If we further remember that the first precise descriptions of BOOP were published at the beginning of the century in cases of nonresolving infectious pneumonia, it is not surprising that infectious processes may sometimes result both in organizing pneumonia and necrosis of the injured parenchyma [14-16]. A practical conclusion is that BOOP seen at the periphery of cavitary pulmonary lesions may be the chronic sequelae of previous inflammatory and partially necrotizing unrecognized infectious injury, the agent being no longer detectable.

When confronted by multiple cavitary nodules together with clinical and biological signs of inflammation, the clinician must also consider the possibility of immunological disorders, such as Wegener's granulomatosis, where BOOP is a rather common feature associated with vasculitis (BOOP may even be prominent and mask the other pathological lesions) $[17,18]$. A careful examination for extrapulmonary signs of vasculitis and the presence of antineutrophil cytoplasmic antibodies is, therefore, necessary in such cases. BOOP is an uncommon finding in pulmonary Langerhans' cell granulomatosis, a disorder often presenting with multiple cavitary nodules, which are, however, generally small and numerous [19]. The pseudometastatic pulmonary nodules seen after bleomycin treatment, which may occasionally be cavitary [20], are another example of pulmonary nodules with BOOP on pathological examination. Finally, it appears that BOOP with cavitary pulmonary lesions is a possible common pathological finding in several types of pulmonary injury of various origin. But can cavitary nodules be the presentation of idiopathic BOOP?

Undoubtedly, cavitary idiopathic BOOP is uncommon. Cavities in solitary masses or nodules have occasionally been mentioned [3, 8, 21-25]. Such cases probably 
correspond to the consequence of inflammatory injury to the lung with focal areas of necrosis in organizing pneumonia. In addition to necrosis as a mechanism of cavity formation, the possibility exists that some cavities are secondary to pneumatocele [26], or that they are preexisting bullous cavities rendered visible by the presence of organizing pneumonia in the adjacent parenchyma. The cases of FroudARAKIS et al. [9] and HARO et al. [10] are especially interesting, in that they emphasize a concrete and original clinical problem: multiple pulmonary cavities of unknown origin, with BOOP on pathological examination. Probably, the main lesson from their studies is that although this imaging presentation is uncommon, as in typical idiopathic BOOP, corticosteroid treatment resulted in complete regression of the inflammatory nodules with no evidence of relapse.

Recognizing idiopathic BOOP as a clinicopathological entity has probably been one of the major advances in clinical research in recent years. However, the clinical and imaging frontiers of this entity seem to be continuously broadening. Whether this reflects reality or merely corresponds to unwarranted inclusion of previously well-known syndromes (organization of diffuse alveolar damage for example) in the spectrum of idiopathic BOOP, will have to be clarified in the future.

\section{References}

1. Colby TV, Myers JL. Clinical and histologic spectrum of bronchiolitis obliterans, including bronchiolitis obliterans organizing pneumonia. Semin Respir Med 1992; 13: 119-133.

2. Cordier JF. Cryptogenic organizing pneumonitis: bronchiolitis obliterans organizing pneumonia. Clin Chest Med 1993; 14: 677-692.

3. Epler GR, Colby TV, McLoud TC, Carrington CB, Gaensler EA. Bronchiolitis obliterans organizing pneumonia. $N$ Engl J Med 1985; 312: 152-158.

4. Davison AG, Heard BE, McAllister WAC, Turner-Warwick ME. Cryptogenic organizing pneumonitis. $Q \mathrm{~J} \mathrm{Med}$ 1983; 52: 382-394.

5. King TE Jr. BOOP: an important cause of migratory pulmonary infiltrates? Eur Respir J 1995; 8: 193-195.

6. Lee KS, Kullnig P, Hartman TE, Muller NL. Cryptogenic organizing pneumonia: CT findings in 43 patients. Am J Roentgenol 1994; 162: 543-546.

7. Haddock JA, Hansell DM. The radiology and terminology of cryptogenic organizing pneumonia. Br J Radiol 1992; 65: 674-680.

8. Flowers JR, Clunie G, Burke M, Constant O. Bronchiolitis obliterans organizing pneumonia: the clinical and radiological features of seven cases and a review of the literature. Clin Radiol 1992; 45: 371-377.

9. Froudarakis M, Bouros D, Loire R, Valasiadou K, Tsiftsis D, Siafakas NM. BOOP presenting with haemoptysis and multiple cavitary nodules. Eur Respir J 1995; 8; 1972-1974.
10. Haro M, Vizcaya M, Texido A, Aguilar X, Arevalo M. Idiopathic bronchiolitis obliterans organizing pneumonia with multiple cavitary lung nodules. Eur Respir J 1995; 8: 1975-1977.

11. Cordier JF, Peyrol S, Loire R. Bronchiolitis obliterans organizing pneumonia as a model of inflammatory lung disease. In: Epler GR, ed. Diseases of the Bronchioles. New York, Raven Press, 1994; pp. 313-345.

12. Fraser RG, Paré JAP, Paré PD, Fraser RS. In: Differential Diagnosis of Diseases of the Chest. Philadelphia; W.B. Saunders Co. 3rd edn. 1991.

13. Logan PM, Primack SL, Miller RR, Müller NL. Invasive aspergillosis of the airways: radiographic, CT and pathologic findings. Radiology 1994; 193: 383-388.

14. Goldstein JD, Godleski JJ, Balikian JP, Herman PG. Pathologic patterns of Serratia marcescens pneumonia. Hum Pathol 1982; 13: 479-484.

15. Anonymous. Case records of the Massachusetts General Hospital (Case 229, 1973). N Engl J Med 1973; 288: 1173-1180.

16. Symmers D, Hoffman AM. The increased incidence of organizing pneumonia. J Am Med Assoc 1923; 81: 297-298.

17. Mark EJ, Matsubara O, Tan-Liu NS, Fienberg R. The pulmonary biopsy in the early diagnosis of Wegener's granulomatosis: a study based on 35 open lung biopsies. Hum Pathol 1988; 19: 1065-1071.

18. Travis WD, Hoffman GS, Leavitt RY, Pass HI, Fauci AS. Surgical pathology of the lung in Wegener's granulomatosis: review of 87 open lung biopsies from 67 patients. Am J Surg Pathol 1991; 15: 315-333.

19. Travis WD, Borok Z, Roum JH, Zhang J, Feurerstein I, Ferrans VJ. Pulmonary Langerhans' cell granulomatosis (histiocytosis X): a clinicopathologic study of cases. Am J Surg Pathol 1993; 17: 971-986.

20. Cohen MB, Austin JH, Smith-Vaniz A, Lutzky J, Grimes MM. Nodular bleomycin toxicity. Am J Clin Pathol 1989; 92: 101-104.

21. Domingo JA, Perez-Calvo JI, Carretero JA, Ferrando J, Cay A, Civeira F. Bronchiolitis obliterans organizing pneumonia: an unusual cause of solitary pulmonary nodule. Chest 1993; 103: 1621-1623.

22. Cordier JF, Loire R, Brune J. Idiopathic bronchiolitis obliterans organizing pneumonia: definition of characteristic clinical profiles in a series of 16 patients. Chest 1989; 96: 999-1004.

23. Alegre-Martin J, Fernandez de Sevilla T, Garcia F, Falco V, Martinez-Vazquez JM. Three cases of idiopathic bronchiolitis obliterans with organizing pneumonia. Eur Respir J 1991; 4: 902-904.

24. Katzenstein AL, Myers JL, Prophet WD, Corley LS III, Shin Ms. Bronchiolitis obliterans and usual interstitial pneumonia: a comparative clinicopathologic study. Am J Surg Pathol 1986; 10: 373-381.

25. Ackerman LV, Elliott G, Alanis M. Localized organizing pneumonia: its resemblance to carcinoma. Am J Roentgenol 1954; 71: 988-996.

26. Linsen VMJ, van Noord JA. A large air-filled cyst in a patient with migratory infiltrates. Chest 1994; 105: 253-254. 